\title{
Correction to: Reduced Foxo3a, FoxL2, and p27 mRNA expression in human ovarian tissue in premature ovarian insufficiency
}

Nikolaos Thanatsis ${ }^{1} \cdot$ Apostolos Kaponis $^{1} \cdot$ Vasiliki Koika $^{2} \cdot$ Neoklis A. Georgopoulos $^{2} \cdot$ George O. Decavalas $^{1}$

Published online: 7 January 2020

(C) Hellenic Endocrine Society 2019

\section{Correction to: Hormones} https://doi.org/10.1007/s42000-019-00134-4

The original version of this article, published 21 October 2019, unfortunately contained a mistake. The presentation of Fig. 1 was incorrect. The corrected figure is given below. The original article has been corrected.

The online version of the original article can be found at https://doi.org/ 10.1007/s42000-019-00134-4

Nikolaos Thanatsis

nikolaos.thanatsis@nhs.net

1 Department of Obstetrics \& Gynecology, Patras University School of Medicine, 26504 Patras, Greece

2 Division of Reproductive Endocrinology, Department of Obstetrics \& Gynecology, Patras University School of Medicine, 26504 Patras, Greece 
a

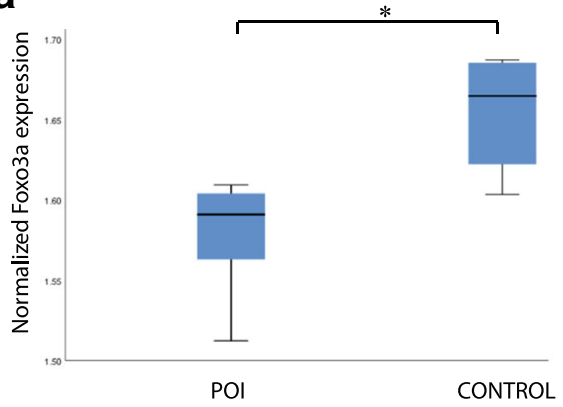

C

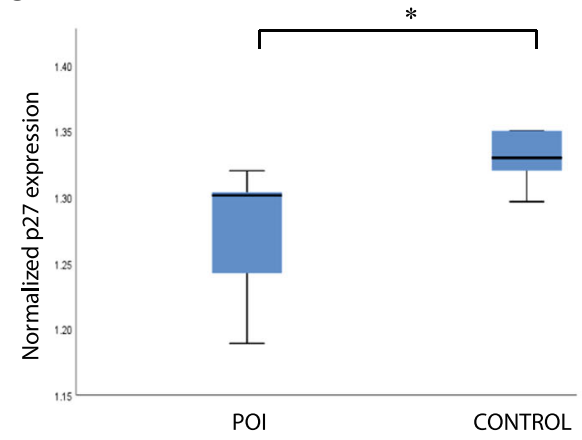

e

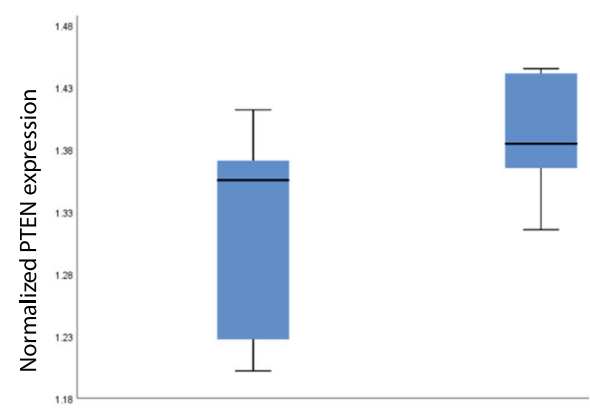

b

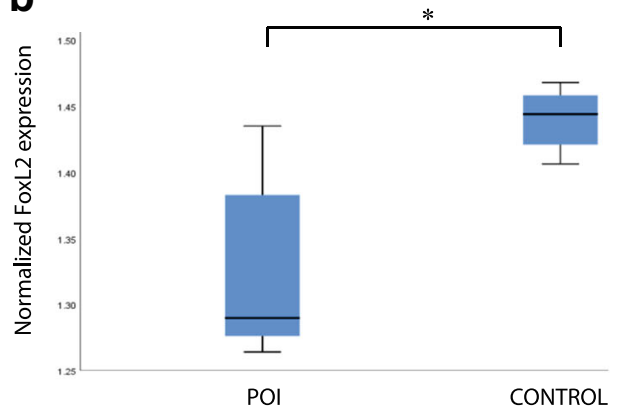

d

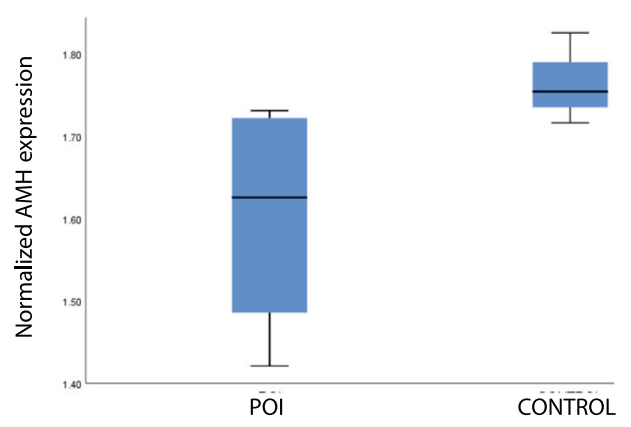

$\mathbf{f}$

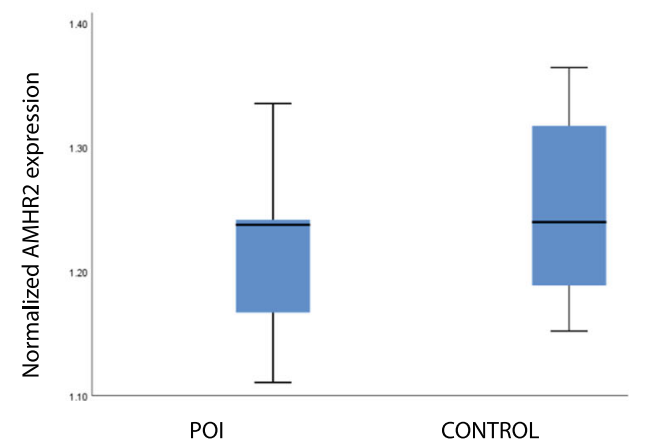

1.4351); control group, 1.4440 (1.4064-1.4680), $P=0.017$. C. p27 - POI group, 1.3014 (1.1891-1.3200); control group, 1.3299 (1.2968-1.4520), $P=0.030$. Statistically insignificant difference was observed in the relative mRNA expression of AMH, PTEN, and AMHR2 between POI women and control women. D. AMH - POI group, 1.6260 (1.4209$1.7315)$; control group, 1.7545 (1.7165-1.8258), $P=0.143$. E. PTEN POI group, 1.3558 (1.2020-1.4121); control group, 1.3848 (1.3159$1.4454), P=0.247$. F. AMHR2 - POI group, 1.2378 (1.1106-1.3353); control group, $1.2399(1.1521-1.3643), P=0.662$

Publisher's note Springer Nature remains neutral with regard to jurisdictional claims in published maps and institutional affiliations. 